\title{
Análise das produções científicas acerca de recursos pedagógicos acessíveis da tabela periódica utilizados no processo de ensino e aprendizagem de alunos surdos
}

Analysis of scientific production related to accessibility resources for the Periodic Table to be used in the teaching and learning proccess of students with hearing loss

Análisis de producciones científicas sobre recursos pedagógicos accesibles desde la tabla periódica utilizada en el proceso de enseñanza y aprendizaje de estudiantes sordos

\section{Lucas Maia Dantas}

Mestrando na Universidade Federal do Rio Grande, Rio Grande, Rio Grande do Sul, Brasil. lucaasmaiadantas@hotmail.com

ORCID - https://orcid.org/0000-0002-0130-671X

Regina Barwaldt

Professora doutora na Universidade Federal do Rio Grande, Rio Grande, Rio Grande do Sul, Brasil. regina.floresta@gmail.com

ORCID - https://orcid.org/0000-0002-0382-3892

\section{Amélia Rota Borges de Bastos}

Professora doutora na Universidade Federal do Pampa, Bagé, Rio Grande do Sul, Brasil. amelia.bastos@unipampa.edu.br ORCID - https://orcid.org/0000-0003-2355-5263

Felipe Vasconcelos Farias Aragão

Graduado na Universidade Federal do Ceará, Fortaleza, Ceará, Brasil.

felipevfaragao@gmail.com

ORCID - https://orcid.org/0000-0002-9235-2681

Recebido em 13 julho 2020

Aprovado em 29 de setembro de 2020

Publicado em 26 de outubro de 2020

\section{RESUMO}

A tabela periódica é um recurso pedagógico utilizado pelos professores como apoio ao processo de ensino e aprendizagem de inúmeros conceitos químicos. Edificá-la como um recurso acessível é condição para a aprendizagem de alunos com surdez em aulas de química. Neste artigo, fruto de um estudo de revisão sistemática, realizamos uma busca de artigos sobre a temática tabela periódica para alunos surdos, com enfoque na existência de termos relacionados aos elementos químicos em LIBRAS e recursos pedagógicos acessíveis para o ensino deste conceito científico, no período de 2015 a 2019. A análise das publicações evidencia que são ainda incipientes os recursos para 0 ensino da tabela periódica ao público surdo. Os materiais existentes se constituem em recursos que buscam pela via visual a apresentação dos conceitos mediados por 
intérpretes em LIBRAS. No que tange a existência de sinais, o estudo identificou apenas oito, número inexpressivo frente ao quantitativo de termos químicos que este conceito envolve. Os resultados apontam para a emergência da proposição de sinais para este conceito químico, de forma a oportunizar aos estudantes surdos o acesso a este importante campo epistêmico.

Palavras-chave: Recursos pedagógicos; tabela periódica; surdos.

\section{ABSTRACT}

The periodic table is a pedagogical resource used by teachers to support the teaching and learning process of numerous chemical concepts. Building it as an accessible resource is a condition to make deaf students' learning process smooth. This article presents the result of a systematic review conducted on the theme "Periodic Table for deaf students", with focus on the availability of terms related to chemical elements in LIBRAS (the brazilian sign language) and of accessible pedagogical resources for teaching this scientific concept, over publications in the 2015 to 2019 time range. The analysis shows that resources for teaching the periodic table to the deaf public are still incipient. The existing materials are resources that seek visual presentation of concepts mediated by interpreters in LIBRAS. Regarding the existence of signs, the study identified only eight, an insignificant number compared to the amount of chemical terms that the Periodic Table concept involves. The results point to the urgency of the proposition of signs for this chemical concept, in order to give deaf students access to this important epistemic field.

Keywords: Pedagogical resources; periodic table; deaf.

\section{RESUMEN}

La tabla periódica es un recurso pedagógico utilizado por los maestros para apoyar el proceso de enseñanza y aprendizaje de numerosos conceptos químicos. Construirlo como un recurso accesible es una condición para aprender a los estudiantes sordos en las clases de química. En este artículo, resultado de un estudio de revisión sistemática, realizamos una búsqueda de artículos sobre la tabla periódica temática para estudiantes sordos, centrándonos en la existencia de términos relacionados con los elementos químicos en LIBRAS y recursos pedagógicos accesibles para enseñar este concepto científico, en el período de 2015 a 2019. El análisis de las publicaciones muestra que los recursos para enseñar la tabla periódica al público sordo siguen siendo incipientes. Los materiales existentes son recursos que buscan la presentación visual de conceptos mediados por intérpretes en LIBRAS. Con respecto a la existencia de signos, el estudio identificó solo ocho, un número insignificante en comparación con la cantidad de términos químicos que implica este concepto. Los resultados apuntan a la urgencia de proponer signos para este concepto químico, con el fin de dar a los estudiantes sordos acceso a este importante campo epistémico.

Palabras clave: Enseñanza de la química; tabla periodica; sordo.

\section{Introdução}

De acordo com a Organização Mundial de Saúde (WHO), existem cerca de 466 milhões de pessoas com perda auditiva incapacitante ${ }^{1}$ no mundo. Estima-se que, no ano de 2050, o número de pessoas com essa especificidade ultrapasse 900 milhões (WHO, 2018). 
http://dx.doi.org/10.5902/1984686X48149

No Brasil, o censo demográfico realizado em 2010 pelo Instituto Brasileiro de Geografia e Estatística (IBGE) registrou cerca de 9,7 milhões de pessoas com deficiência auditiva. Deste total, cerca de 2,2 milhões possuem deficiência auditiva em situação severa, e, entre estes, 344,2 mil são surdos (IBGE, 2010).

Segundo o Instituto Nacional de Estudos e Pesquisas Educacionais Anísio Teixeira (INEP), em seu Censo Escolar realizado em 2018, o número de matrículas de alunos com deficiência, transtornos globais do desenvolvimento e/ou altas habilidades/superdotação em classes comuns (incluídos), ou em classes especiais exclusivas, chegou a 1,2 milhão em 2018, um aumento de 33,2\% em relação a 2014.

Considera-se surda aquela pessoa que possui perda auditiva profunda, ou seja, escuta pouco os sons muito altos ou não escuta som algum, interagindo com o mundo principalmente pela via visual e usando, muitas vezes, das diversas línguas de sinais (WHO, 2018). Essa afirmação é reforçada, no Brasil, pelo artigo $2^{\circ}$ do decreto 5.626 de 22 de dezembro de 2005, que define surdo como aquela pessoa que, por ter perda auditiva, compreende e interage com o mundo por meio de experiências visuais, manifestando sua cultura principalmente pelo uso da Língua Brasileira de Sinais - LIBRAS (BRASIL, 2005).

O sujeito surdo possui uma forma particular de ver o mundo, interagindo com ele por meio do campo visual e gestual, diferentemente do sujeito ouvinte que se utiliza da audição, da fala e visão (ZIESMANN, 2015). Dentre as principais barreiras vivenciadas por esses sujeitos ao longo da vida, destacam-se as barreiras da comunicação, da aquisição da linguagem, de ser atendido e de atenderem suas necessidades em diferentes contextos, uma vez que é a partir de uma língua que advém o pertencimento a uma comunidade e se constituem as identidades e demais aprendizagens (ZUCOLOTTO, RUIZ, PINHEIRO, 2019).

A garantia de alguns direitos importantes para a comunidade surda ainda são conquistas recentes na história do Brasil. No âmbito da educação, cabe destacar que: a Constituição Federativa do Brasil de 1988, no artigo 208, prevê que a inclusão de alunos com deficiência deve ocorrer, preferencialmente, na rede regular de ensino (BRASIL, 1988). A Lei de Diretrizes e Bases (LDB) de 1996 também recomenda que a educação desses alunos ocorra na rede regular de ensino (BRASIL, 1996). Em complemento, a Lei Brasileira de Inclusão (LBI), n. 1.146, no artigo 28, garante ao surdo, em seu inciso II, condições de acesso, permanência, participação e aprendizagem, por meio da oferta de serviços e de recursos de acessibilidade que eliminem as barreiras e promovam a inclusão plena e, no 
http://dx.doi.org/10.5902/1984686X48149

inciso III, o pleno acesso ao currículo em condições de igualdade, promovendo a conquista e o exercício de sua autonomia (BRASIL, 2015). Outra conquista importante para a comunidade surda veio com a publicação da lei 13.409 de 28 de dezembro de 2016, que inclui pessoas com deficiência no sistema de cotas adotados por universidades e escolas técnicas federais (BRASIL, 2016).

Em 24 de abril de 2002, a Língua Brasileira de Sinais (LIBRAS) foi oficializada através da lei 10.436. Ela garante à comunidade surda o direito de se comunicar em sua língua natural em ambientes como a escola. Assim, a LIBRAS é considerada a primeira língua para a pessoa surda e, no caso do Brasil, a Língua Portuguesa é a segunda língua (BRASIL, 2002).

A partir desse momento, a consolidação da LIBRAS como língua de instrução e acessibilidade é evidenciada, e com a presença do profissional intérprete é possível encontrá-la em diferentes contextos, como ambientes culturais e artísticos (museus, por exemplo), propagandas eleitorais, eventos acadêmicos e programas televisivos, reforçando o protagonismo do sujeito surdo em contextos acadêmicos, profissionais e sociais (DE SÁ, CRUZ E PINHEIRO, 2020).

No Brasil, é por meio da LIBRAS que os surdos constroem sua subjetividade, se inserem no processo dialógico de sua comunidade e adquirem novas concepções de mundo. Desse modo, ressalta-se a necessidade de que crianças surdas estejam em contato com adultos surdos fluentes em LIBRAS para poder se apropriar de sua língua natural e para que, a partir desse momento, possam significar o mundo (CAPORALLI, DIZEU, 2005). A Federação Nacional de Educação e Interação dos Surdos (FENEIS) é responsável por representar a comunidade surda no Brasil, contribuindo para propagação da LIBRAS, defendendo uma política de inclusão de pessoas com surdez no meio social por meio do bilinguismo e reivindicando a presença de intérpretes em todos os órgãos públicos e mídia (REILY, 2004).

Entretanto, é importante ressaltar que a presença do profissional intérprete em sala de aula e o uso da língua de sinais, somente, não garantem que as condições específicas da surdez sejam contempladas e respeitadas nas atividades pedagógicas. Fatores como escolha da metodologia utilizada e currículo proposto podem contribuir para que as práticas acadêmicas continuem inacessíveis ao aluno surdo (LACERDA, POLETTI, 2009).

O processo de ensino e aprendizagem de alunos surdos encontra dificuldades em componentes curriculares específicos, como a Química, que necessita da compreensão 
http://dx.doi.org/10.5902/1984686X48149

dos níveis representacionais microscópico, macroscópico e simbólico e possui alto grau de abstração. Somando a isso, as aulas são ministradas pelo professor em Língua Portuguesa, segunda língua para o surdo, e traduzidas para LIBRAS pelo intérprete (CHARALLO, FREITAS, ZARA, 2018; OLIVEIRA E BENITE, 2015). Entretanto, há uma ausência de sinais-termo representativos para diversos termos químicos (PEREIRA et. al., 2011; SALDANHA, 2011; REIS, 2015, SANTOS et. al., 2018).

Nogueira, Barroso e Sampaio (2018) ressaltam que, apesar da aprendizagem poder ser facilitada por ações como a didática do professor e recursos utilizados, a língua é um fator insubstituível. É por meio dela que os surdos terão acesso à informação e irão interagir com seus semelhantes, assimilando comportamentos, definições, formas de pensar e cultura, e poderão se desenvolver para entender o mundo e a si.

\section{Evolução da Tabela Periódica}

A Química é a ciência responsável por estudar a composição, a estrutura, as propriedades da matéria, as suas mudanças durante as reações químicas e a sua relação com a energia (FNDE, 2020). Os elementos químicos são considerados os constituintes básicos de toda substância, cada um deles possui características específicas que os diferenciam e os assemelham. Entender as condições necessárias para que essas interações ocorram, é fundamental para o ensino e aprendizagem de Química.

Ao longo da história, diversos cientistas buscaram organizar as informações descobertas referentes aos elementos. Dentre as principais propostas, destacam-se: a do geólogo francês Alexandre Émile Béguyer de Chancourtois, que em 1862 propôs uma organização por meio dos pesos atômicos em um eixo vertical cilíndrico formando uma espiral; a do químico britânico William Odling, que em 1864 propôs uma forma de organização dos elementos em 13 grupos de acordo com suas propriedades e em ordem crescente do peso atômico; a do químico e músico John Alexander Reina Newlands, que em 1866, com a chamada Lei das Oitavas, percebeu que, para elementos que diferenciam seu peso atômico por sete, havia similaridade entre suas propriedades. A Lei das Oitavas foi um comparativo às oito notas musicais pois, segundo Newlands, a propriedade de uma substância se repetia na oitava, seguindo uma ordem crescente dos pesos atômicos; a do médico Julius Lothar Meyer, que entre os anos 1864 a 1870, também sugeriu uma sequência de proposições de organização dos elementos em forma de tabela de acordo com sua valência, incorporando-a com novos grupos de elementos a cada publicação até 
http://dx.doi.org/10.5902/1984686X48149

chegar em um modelo que considerava o peso atômico e a valência dos elementos, organizando-os em linhas verticais, entretanto, não publicou esta última versão (LEITE, 2019).

O marco da história da tabela periódica aconteceu no ano de 1869, quando o russo Dimitri Ivanovic Mendeleev apresentou à Sociedade Russa de Química seu primeiro diagrama de organização dos elementos. O fato de Mendeleev deixar espaços vazios e reservados em sua tabela, sugerindo a existência de elementos não descobertos, foi o grande diferencial dessa proposta. Ao longo dos anos, diversas adaptações foram realizadas e elementos foram adicionados para completar as lacunas previstas (LEITE, 2019).

Das novas descobertas ocorridas na virada do século XIX para o século XX, destacase que a melhor forma de organização seria por número atômico, ou seja, número de prótons no núcleo de cada tipo de átomo (LOPES, HÖLZLE, 2019).

Atualmente, a tabela periódica possui 7 linhas e 18 colunas e organiza os elementos químicos em ordem crescente de número atômico (Z). Nela, as linhas representam períodos e as colunas representam grupos/famílias. Os elementos localizados na mesma coluna possuem características físico-químicas semelhantes (FERREIRA, 2005).

A lista de 118 elementos espalhados pelas linhas e colunas da tabela é o alfabeto que nos ajuda a ler a história do Universo e compreender como cada forma de vida funciona. $\mathrm{O}$ estudo dos elementos químicos é o principal alicerce no ensino de Química, desde a história da origem destes até a sua composição fundamental (LOPES, HÖLZLE, 2019).

A Tabela Periódica atua não apenas como um catálogo de todos os átomos conhecidos do universo, seu desenvolvimento constitui-se como um dos mais significativos acontecimentos da ciência e é considerado um conceito unificador, com encadeamentos na Química, Física, Biologia e em outras ciências, auxiliando a compreensão e a previsibilidade de características da terra e do universo. (DA SILVA et. al., 2016; LEITE, 2019; LOPES, HÖLZLE, 2019).

\section{Tabela periódica como recurso didático}

A tabela periódica é um recurso presente em laboratórios e livros de química geral do mundo todo. Sua apresentação e explicação modificou-se ao longo dos anos por razões que envolvem a abordagem dada à química em cada época, local, contexto histórico e natureza de temas incluídos em cursos e livros de química geral. Mesmo assim, a tabela 
http://dx.doi.org/10.5902/1984686X48149

tornou-se um dos principais assuntos da matriz curricular do ensino básico, já que o mesmo remete ao conceito de átomo e acaba englobando os modelos atômicos. (LEITE, PORTO, 2015; DA ROCHA, LEAL, MESSEDER, 2019).

As informações encontradas na tabela periódica tradicional correspondem ao nome de cada elemento, seu símbolo químico e seu número atômico. Entretanto, é possível encontrar tabelas mais completas, com informações sobre propriedades atômicas e propriedades físicas (BARRETO et. al., 2016).

Para Luca et. al. (2015) a tabela periódica atua como um recurso didático que se interpõe entre o estudante e o mundo. Os autores afirmam que a tabela periódica:

\begin{abstract}
constitui-se um material imprescindível no Ensino de Química e um instrumento facilitador das relações interdisciplinares, [...] pois reúne informações importantes para a compreensão de diversos conceitos, entre eles: elemento químico, massa atômica, número atômico, estrutura atômica, lei periódica, constituição celular, fisiologia histológica e organológica dos seres vivos; seus dados promovem a compreensão dos processos químicos, estreitando as relações dos meios científico, cultural e social (LUCA et. al., 2015, p.14)
\end{abstract}

Quando se trata das dificuldades encontradas quanto ao ensino da tabela periódica, alguns autores criticam métodos que levam os alunos apenas a decorar símbolos e nomes. Flôr (2008) nos diz que:

"Na educação em química, tanto no ensino fundamental quanto no ensino médio, os estudos sobre a tabela periódica são de fundamental importância para a compreensão dos diversos conceitos químicos. Estes estudos, porém, geralmente se dão de forma fragmentada, por exemplo, quando os professores mandam "decorar" os nomes dos elementos pertencentes a cada família” (FLÔR, 2008, p. 2).

Ferreira e Arroio (2009) explicam que as maiores dificuldades encontradas estão, principalmente, quando os alunos não conseguem perceber as relações entre os elementos químicos e o meio em que vivem. Araújo, Nunes e Rezende (2019) complementam que mesmo que alguns elementos apresentem propriedades semelhantes, diferentes aplicabilidades podem ser encontradas no dia a dia. Entretanto, tais aplicações nem sempre são apresentadas e trabalhadas em livros didáticos, por exemplo, acontecendo apenas uma exposição exaustiva de cada elemento e suas características. Ribeiro e Da Silva (2016) somam à essa questão a ausência de experimentação e da história da ciência em aulas relacionadas ao tema.

Em contrapartida, mesmo reconhecendo as questões apresentadas acima, alguns autores mostram que, apesar ter sido utilizada de forma que o aluno apenas decorasse 
http://dx.doi.org/10.5902/1984686X48149

nomes e símbolos químicos, sem realizar reflexão, a tabela periódica também é vista como um recurso que possibilita relacionar o uso dos elementos a temas do cotidiano (DOS SANTOS, ARAÚJO, 2017; MOURA, 2014).

Cabe destacar que existem inúmeras formas de se trabalhar seus conceitos em sala de aula, indo desde $\mathrm{o}$ uso do livro didático até mesmo imagens e modelos representacionais, jogos didáticos, softwares, ambientes virtuais de aprendizagens, vídeos, atividades experimentais, entre outros.

Godoi, Oliveira e Codognoto (2010) relatam que cabe ao professor de química escolher a forma de apresentação desses conceitos ao aluno, procurando sempre trazer elementos mais significativos, métodos de preparação, aplicações do cotidiano e correlações desse conteúdo com todos os outros conteúdos estudados durante o ano.

\section{Educação de Surdos em Química}

Ao longo da história, a educação dos surdos foi e é marcada por conflitos de pensamentos que se dividem, principalmente, entre gestualistas, que defendem o uso da língua de sinais, e oralistas, que defendem o uso da comunicação oral (PONTARA, 2017). Três vertentes destacaram-se e influenciaram a história da educação dos surdos, sendo elas: Oralismo, a Comunicação Total e a Educação Bilíngue ou Bilinguismo.

O oralismo defendia o aprendizado apenas da língua oral e a utilização de sinais era rigorosamente proibida, pois acreditava-se que seu uso impedia a aquisição e desenvolvimento da língua oral. Nessa vertente, a surdez era considerada uma deficiência que devia ser minimizada por meio da estimulação auditiva, pelo uso de prótese e por atendimentos especializados, pois esperava-se que a criança surda pudesse se habilitar para falar e interagir com o mundo por meio da língua oral. Com o tempo, percebeu-se que essa proposta não proporcionou desenvolvimento satisfatório aos alunos surdos, uma vez que os manteve distantes das informações e possibilidades de desenvolvimento (MEIRELES, 2010; CRUZ E PRADO, 2018).

A Comunicação Total surge pouco depois da primeira publicação referente ao primeiro estudo linguístico sobre a Língua de Sinais Americana (ASL) realizado por Wilian Stokoe nos Estados Unidos. Após iniciou-se o processo de valorização da língua de sinais. Essa proposta pedagógica se opôs à rigidez e aos princípios limitadores do Oralismo, uma vez que o surdo não era mais proibido de usar a língua de sinais e a surdez deixou de ser vista como patologia. A Comunicação Total defendia o uso de diversos recursos que facilitam a 
http://dx.doi.org/10.5902/1984686X48149

comunicação e o desenvolvimento biopsicossocial do surdo, como língua de sinais, língua oral, códigos, pantomimas, escrita, gestos naturais, treinamento auditivo, leitura labial, alfabeto manual, português sinalizado e outros (CRUZ, PRADO, 2018).

Todavia, o uso da língua não ocorria de maneira plena, pois essa vertente não reconheceu a língua de sinais como um sistema constituído de valores e regras gramaticais e não reconheceu seu valor cultural. O objetivo continuou sendo a aprendizagem da língua oral com intenção de promover a comunicação entre surdos e ouvintes a qualquer custo, fazendo uso das duas línguas simultaneamente. Como consequência, a comunicação total contribuiu para desestruturar ambas as línguas, causando conflito no desenvolvimento do pensamento de indivíduos surdos (CRUZ, PRADO, 2018).

Por volta da década de 80, surge uma nova concepção conhecida como Educação Bilíngue ou Bilinguismo. Nela, a surdez é discutida como uma experiência visual e distinta da experiência ouvinte e, desse modo, é reconhecido que não se deve igualar o surdo ao ouvinte, sendo importante delimitar espaços e reafirmar a surdez como diferença linguística e cultural. Assim, a Educação Bilíngue é uma proposta pedagógica que objetiva o desenvolvimento global do surdo por intermédio de duas línguas, no caso do Brasil, a LIBRAS como primeira língua (L1) e a Língua portuguesa escrita como segunda língua (L2), ou seja, a Educação Bilíngue permite que o surdo aprenda a língua majoritária usada pelos ouvintes, na modalidade escrita, sem deixar de usar a língua de sinais como primeira língua, possibilitando melhores resultados na aprendizagem escolar e na inclusão social. 0 surdo, para os bilinguistas, não precisa almejar uma vida semelhante ao ouvinte, podendo aceitar e assumir a surdez, pois, nesse modelo, os surdos podem formar uma comunidade com cultura e língua próprias (GOLDFELD, 2003; LUZ, 2016; MEIRELES, 2010; CRUZ, PRADO, 2018).

Entre os três modelos descritos, a Educação Bilíngue parece oferecer melhores condições para a aquisição da comunicação por surdos e tem ocupado espaço no cenário científico mundial em países como EUA, Canadá, Suécia, Venezuela, Israel, e outros países que desenvolvem pesquisas sobre surdez e abordagem bilíngue (GOLDFELD, 2003).

Perlin e Strobel (2006) destacam que a educação surda deve basear-se na pedagogia surda, onde a diferença linguística e cultural em que esses sujeitos estão imersos deve ser evidenciada, pois o surdo é reconhecido como um sujeito completo e sua capacidade de interpretação e comunicação visual deve ser valorizada, mesmo considerando a ausência 
http://dx.doi.org/10.5902/1984686X48149

do sentido da audição, chamando atenção para que o processo de ensino e aprendizagem de alunos surdos envolva atividades visuais de modo a possibilitar a leitura de imagens e construção de significados de forma interdependente à constituição do pensamento. Em complemento, Almeida et al. (2007) destacam o elemento visual como um dos principais facilitadores do desenvolvimento e aprendizagem do surdo e orientam que as estratégias metodológicas utilizadas na educação de crianças surdas devem privilegiar os recursos visuais como meio facilitador da criatividade, do pensamento, da linguagem gestual, oral e escrita.

No âmbito do ensino de Química, os surdos enfrentam dificuldade no processo de ensino e aprendizagem, pois existe uma carência de sinais em LIBRAS que representem conceitos e vocabulários específicos, até mesmo para palavras elementares da área, além de uma ausência de palavras de ligação que Ihes configurem significado.

$\mathrm{Na}$ ausência de sinais correspondentes em LIBRAS de termos científicos da língua portuguesa, os intérpretes buscam passar conceitos que desconhecem e usam estratégias como a datilologia ou negociar sinais momentâneos, necessários só para uma determinada aula (BARRAL et. al., 2017; CHARALLO et. al., 2018; LACERDA, 2006).

A datilologia é a utilização do alfabeto manual para expressar uma palavra ou nome. Neste recurso, cada sinal corresponde a uma letra (querema) e sua utilização ocorre quando se soletram as palavras através das mãos, pois a palavra não possui um sinal específico. Entretanto, alerta-se que a comunicação não deve acontecer traduzindo as letras de cada palavra e ressalta-se que a língua de sinais é constituída por sinais que correspondem a objetos, pronomes, verbos, substantivos, entre outros (HONORA, 2014; REIS, 2015).

Marinho (2007) faz um alerta quanto ao uso da datilologia pelos intérpretes. Para a autora, este recurso:

[...] não é bem quisto por três razões: (i) a rapidez da soletração impede muitas vezes o reconhecimento da palavra pelo surdo; (ii) muitos termos são de origem grega ou latina e, neste caso, é comum o intérprete digitar letras erradas por desconhecimento da grafia português; (iii) a forma sem acesso à substância dificulta a formação de conceitos. Os demais recursos, imagens ou figuras, nem sempre estão disponíveis no ato da interpretação (MARINHO, 2007, p. 33).

Chassot (2003), ao falar do processo de alfabetização científica, defende a ciência como uma linguagem e afirma que ser alfabetizado cientificamente é saber ler a linguagem da ciência. $O$ autor afirma que: 
http://dx.doi.org/10.5902/1984686X48149

A ciência pode ser considerada como uma linguagem construída pelos homens e pelas mulheres para explicar o nosso mundo natural. Compreendermos essa linguagem (da ciência) como entendemos algo escrito numa língua que conhecemos (por exemplo, quando se entende um texto escrito em português) é podermos compreender a linguagem na qual está (sendo) escrita a natureza. Também é verdade que nossas dificuldades diante de um texto em uma língua que não dominamos podem ser comparadas com as incompreensões para explicar muitos dos fenômenos que ocorrem na natureza. Por exemplo, é provável que alguns dos leitores deste texto não saibam distinguir se uma página de um livro ou de uma revista está escrito em sueco ou em norueguês, assim como deve haver nórdicos que talvez não reconheçam a diferença entre um texto em português e um em espanhol. Essa é a analogia que busco quando falo na ciência como uma linguagem (CHASSOT, 2003. p. 91)

É possível relacionar a analogia descrita acima com a realidade vivenciada por alunos surdos em aulas de Química, uma vez que a língua natural desses sujeitos (LIBRAS) não possui sinais suficientes para representar os termos químicos, ou seja, esses sujeitos precisam ler e interpretar utilizando uma segunda língua (Língua Portuguesa na modalidade escrita), nem sempre fluente, para compreender a linguagem da ciência.

Charallo, Freitas e Zara (2018) orientam que, para minimizar a barreira presente na aprendizagem de surdos na área de ciências devido a não disponibilidade de todas as terminologias específicas a compreensão dos conceitos, o professor precisa adotar estratégias de comunicação que valorizem a utilização de recursos visuais associada à interpretação em LIBRAS da linguagem técnica da área, pois para os autores, a comunicação conjugada, por meio de sinais associados a aulas privilegiando o uso de recursos visuais podem possibilitar ao aluno surdo participação e vivências significativa a construção de seu conhecimento científico como agente do processo que irá fortalecer a Língua de Sinais.

Por fim, cabe esclarecer uma diferença importante quanto ao sinal e ao termo. Faulstich (2014) explica essa diferença conceituando cada um deles por meio de uma nota lexical publicada na sua página, para a autora:

Sinal. 1. Sistema de relações que constitui de modo organizado as línguas de sinais. 2. Propriedades linguísticas das línguas dos Surdos. Nota: a forma plural -sinais- é a que aparece na composição língua de sinais. Termo. Palavra simples, palavra composta, símbolo ou fórmula que designam os conceitos de áreas especializadas do conhecimento e do saber. Também chamado unidade terminológica (FAULSTICH, 2014, p.1).

Surge então a necessidade de uma nova expressão para definir sinais que se diferenciam daqueles considerados comuns. A autora propõe uma nova expressão chamada sinal-termo. Ela faz referência a termos especializados, científicos ou técnicos, 
com significado no contexto das linguagens específicas, como aqueles encontrados na Química, Física e Biologia. Faulstich (2012) define sinal-termo como:

\begin{abstract}
Sinal-termo. 1. Termo da Língua de Sinais Brasileira que representa conceitos com características de linguagem especializada, próprias de classe de objetos, de relações ou de entidades. 2. Termo criado para, na Língua de Sinais Brasileira, denotar conceitos contidos nas palavras simples, compostas, símbolos ou fórmulas, usados nas áreas especializadas do conhecimento e do saber. 3. Termo adaptado do português para representar conceitos por meio de palavras simples, compostas, símbolos ou fórmulas, usados nas áreas especializadas do conhecimento da Língua de Sinais Brasileira (FAULSTICH, 2012, p. 1).
\end{abstract}

Desse modo, a diferença entre sinal e sinal-termo mostra que o surgimento do sinal acontece de acordo com a necessidade linguística da língua comum, enquanto o surgimento do sinal-termo ocorre da precisão de um sinal para representar e conceituar os vocábulos, na língua de sinais, que estejam dentro do contexto de áreas específicas e tecnológicas, embasado em conceitos abstratos e definições de determinado objeto da área (SANTOS, 2017). Portanto, o objetivo desta pesquisa foi realizar uma revisão sistemática de artigos sobre a temática tabela periódica para alunos surdos, com enfoque na existência de termos relacionados aos elementos químicos em LIBRAS e recursos pedagógicos acessíveis para o ensino deste conceito científico, no período de 2015 a 2019.

\title{
Metodologia da revisão sistemática
}

Uma revisão sistemática é uma forma de pesquisa que utiliza como fonte de dados a literatura sobre determinado tema. Autores ainda ressaltam que este tipo de revisão objetiva identificar, avaliar e interpretar as pesquisas relevantes sobre determinada temática a fim de responder um questionamento de pesquisa bem delimitado (KITCHENHAM, 2004; SAMPAIO, MANCINI, 2007).

As revisões sistemáticas possuem a utilidade de integrar as informações a respeito de um conjunto de estudos realizados sobre determinada terapêutica/intervenção, podendo apresentar resultados conflitantes e/ou coincidentes, tal como identificar temas que necessitam de evidência, auxiliando na orientação para investigações futuras (SAMPAIO, MANCINI, 2007).

A descrição das etapas da revisão sistemática ocorre conforme a Figura 1: 
http://dx.doi.org/10.5902/1984686X48149

Figura 1 - Etapa da Revisão Sistemática

Definir a pergunta cientifica, especificando populaça e intervença de interesse

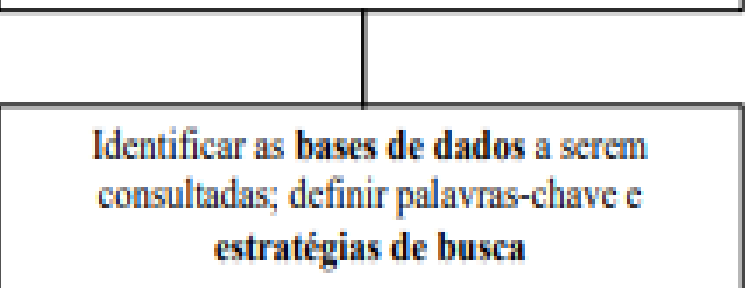

Estabelecer critérios para a seleça dos artigos a partir da busca

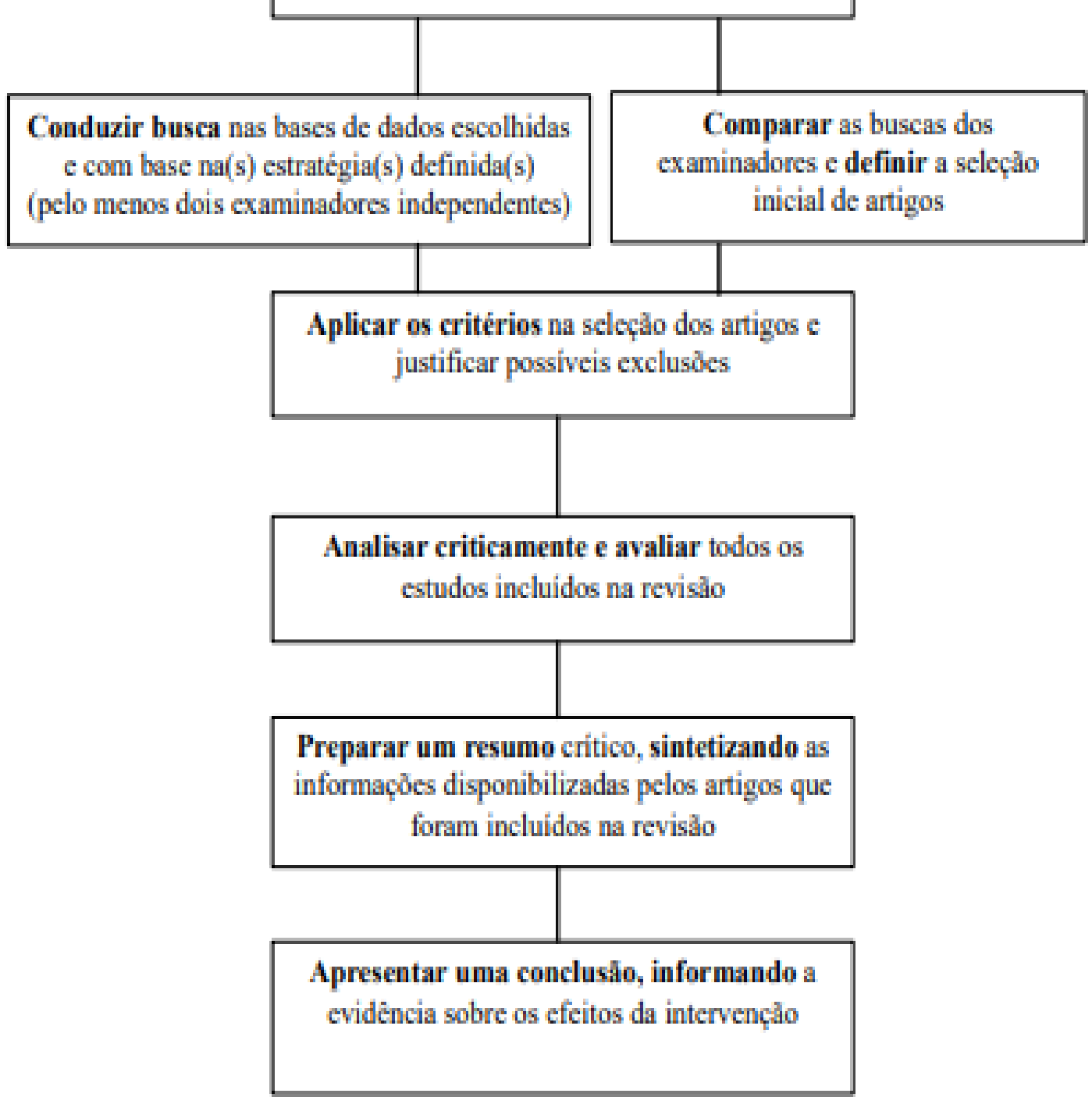

Fonte: Sampaio e Mancini (2007). 


\section{Questões de Pesquisa}

Neste trabalho foram formuladas as seguintes questões de pesquisa, conforme 0 Quadro 1.

Quadro 1 - Questões de Pesquisa

\begin{tabular}{|l|l|}
\hline & Questões de Pesquisa \\
\hline QP1 & Existem recursos pedagógicos acessíveis para o ensino da tabela periódica para alunos surdos? \\
\hline QP2 & Como ocorre o ensino referente aos conceitos da tabela periódica para alunos surdos? \\
\hline QP3 & Existem sinais que representam os elementos químicos em língua de sinais para alunos surdos? \\
\hline
\end{tabular}

Fonte: Autores (2020).

\section{Bases de dados pesquisadas}

A escolha das bases de dados englobou eventos e revistas da área de química, informática, ensino de química e ensino de ciências. A busca também foi realizada no portal de periódicos CAPES, que possui bases indexadas, como Scielo, Science direct, dentre outras. As bases escolhidas estão dispostas no Quadro 2, abaixo:

Quadro 2 - Bases de busca

\begin{tabular}{|l|l|}
\hline \multicolumn{2}{|l|}{ Bases } \\
\hline IEEE Xplore & Biblioteca digital que agrega conteúdo sobre inovação tecnológica \\
\hline CBQ & Congresso Brasileiro de Química \\
\hline ENEQ & Encontro Nacional de Ensino de Química \\
\hline SIMPEQUI & Simpósio Brasileiro de Educação Química \\
\hline EDEQ & Encontro de Debates sobre o Ensino de Química \\
\hline ENPEC & Encontro Nacional de Pesquisa em Educação em Ciências \\
\hline QNESC & Revista Química Nova na Escola \\
\hline Química Nova & Revista Química Nova \\
\hline REDEQUIM & Revista Debates em Ensino de Química \\
\hline SBIE & Simpósio Brasileiro de Informática Na Educação \\
\hline Portal CAPES & Portal de Periódicos CAPES (Conselho de Aperfeiçoamento de Pessoal de Nível Superior) \\
\hline
\end{tabular}

Fonte: Autores (2020). 


\section{String de busca}

Para realizar a busca das publicações relacionadas ao tema da pesquisa, construiu-se uma string base utilizando três palavras chave e suas respectivas traduções para língua inglesa. As três palavras chave escolhidas foram: ensino de química, tabela periódica e surdos/surdez.

A construção da string base seguiu a seguinte lógica:

$(\mathrm{A}$ e $\mathrm{B})$ ou $(\mathrm{C}$ e $\mathrm{B})=(\mathrm{A}$ ou $\mathrm{C})$ e $\mathrm{B}$

$\mathrm{A}=$ tabela periódica $\mathrm{OR}$ periodic table

$\mathrm{B}=$ surdos $\mathrm{OR}$ surdez $\mathrm{OR}$ deaf $\mathrm{OR}$ deafness

$\mathrm{C}=$ ensino de química $\mathrm{OR}$ chemistry teaching

A seguir observa-se a string: ((tabela periódica OR periodic table OR ensino de química OR chemistry teaching) AND (surdos OR surdez OR deaf OR deafness))

Vale ressaltar que cada base de dados possui a sua particularidade na sintaxe da string de busca e, para minimizar essas diferenças, algumas adaptações foram realizadas durante o momento de recuperação dos documentos.

Uma observação necessária é que no Portal de Periódicos da CAPES foram selecionados apenas artigos revisados pelos pares.

A busca foi conduzida por dois pesquisadores de forma separada e ao final comparadas antes da seleção inicial de artigos. No Quadro 3 é possível observar a quantidade de publicações localizadas em cada uma das bases. 
http://dx.doi.org/10.5902/1984686X48149

Quadro 3 - Quantidade de publicações localizadas

\begin{tabular}{|l|l|}
\hline Bases & Publicações localizadas \\
\hline IEEE Xplore & 0 \\
\hline CBQ & 8 \\
\hline ENEQ & 41 \\
\hline SIMPEQUI & 6 \\
\hline EDEQ & 8 \\
\hline ENPEC & 26 \\
\hline QNESC & 8 \\
\hline Química Nova & 4 \\
\hline REDEQUIM & 3 \\
\hline SBIE & 4 \\
\hline Portal Capes & 946 \\
\hline Total & 1054 \\
\hline
\end{tabular}

Fonte: Autores (2020).

\section{Critérios de inclusão}

Foram considerados apenas publicações que abordavam a temática: ensino da tabela periódica ou elementos químicos em língua de sinais para alunos surdos.

\section{Critérios de exclusão}

Foram excluídas publicações que não se encontravam na faixa temporal de 2015 a 2019, não possuíam seu texto disponível na íntegra, não contemplavam materiais ou métodos para o ensino da tabela periódica ou dos elementos químicos para alunos surdos e também aquelas que não correspondiam aos idiomas português, inglês e espanhol.

\section{Resultados da revisão sistemática}

O Quadro 4 mostra a quantidade de publicações selecionadas após a utilização dos critérios de exclusão. 
http://dx.doi.org/10.5902/1984686X48149

Quadro 4 - Quantidade de publicações selecionadas

\begin{tabular}{|l|l|l|}
\hline Bases & Publicações localizadas & Publicações selecionadas \\
\hline IEEE Xplore & 0 & 0 \\
\hline CBQ & 8 & 2 \\
\hline ENEQ & 41 & 1 \\
\hline SIMPEQUI & 6 & 0 \\
\hline EDEQ & 8 & 1 \\
\hline ENPEC & 26 & 0 \\
\hline QNESC & 8 & 0 \\
\hline Química Nova & 4 & 0 \\
\hline REDEQUIM & 3 & 1 \\
\hline RBIE & 4 & 0 \\
\hline Portal Capes & 946 & 3 \\
\hline Total & 1054 & 8 \\
\hline
\end{tabular}

Fonte: Autores (2020).

O Quadro 5 apresenta a caracterização das publicações selecionadas: autores, país e ano de publicação, materiais e/ou métodos utilizados, se a publicação utiliza línguas de sinais e se a publicação propõe sinais para elementos químicos.

Quadro 5 - Caracterização dos artigos selecionados

(continua)

\begin{tabular}{|l|l|l|l|l|l|l|l|}
\hline Autores & Título & Ano & Publicado em & País & Materiais/ & $\begin{array}{l}\text { Utiliza } \\
\text { língua } \\
\text { de sinais }\end{array}$ & $\begin{array}{l}\text { Propõe sinal } \\
\text { para } \\
\text { elementos } \\
\text { químicos }\end{array}$ \\
\hline $\begin{array}{l}\text { Souza e Rocha } \\
\text { et. al. }\end{array}$ & $\begin{array}{l}\text { Bancada eletrônica de } \\
\text { elementos químicos da } \\
\text { tabela periódica para } \\
\text { alunos com surdez e } \\
\text { cegueira. }\end{array}$ & 2015 & $\begin{array}{l}\text { 55o Congresso } \\
\text { Brasileiro de } \\
\text { Química. }\end{array}$ & Brasil & $\begin{array}{l}\text { Bancada eletrônica de } \\
\text { elementos químicos da } \\
\text { tabela periódica com } \\
\text { materiais reaproveitados. }\end{array}$ & Sim & Não \\
\hline
\end{tabular}


http://dx.doi.org/10.5902/1984686X48149

Quadro 5 - Caracterização dos artigos selecionados

\begin{tabular}{|c|c|c|c|c|c|c|c|}
\hline Autores & Título & Ano & Publicado em & País & $\begin{array}{l}\text { Materiais/ } \\
\text { Métodos }\end{array}$ & $\begin{array}{l}\text { Utiliza } \\
\text { língua } \\
\text { de sinais }\end{array}$ & $\begin{array}{l}\text { Propõe sinal } \\
\text { para } \\
\text { elementos } \\
\text { químicos }\end{array}$ \\
\hline Carvalho et. al & $\begin{array}{l}\text { A elaboração de } \\
\text { material didático sobre } \\
\text { o conteúdo de } \\
\text { ligações químicas, } \\
\text { iônica e covalente, } \\
\text { voltado para o ensino } \\
\text { do aluno surdo: uma } \\
\text { proposta de sinais. }\end{array}$ & 2016 & $\begin{array}{l}\text { XVIII Encontro } \\
\text { Nacional de } \\
\text { Ensino de } \\
\text { Química. }\end{array}$ & Brasil & $\begin{array}{l}\text { Apresentações no Prezi, o } \\
\text { Periodic Table, e o uso de } \\
\text { uma tabela } \\
\text { periódica interativa. }\end{array}$ & Sim & Não \\
\hline $\begin{array}{l}\text { Bastos, Dantas } \\
\text { e Teixeira. }\end{array}$ & $\begin{array}{l}\text { Tabela Periódica } \\
\text { Acessível: da } \\
\text { proposição do recurso } \\
\text { à implementação no } \\
\text { ensino de alunos com } \\
\text { deficiência visual. }\end{array}$ & 2017 & $\begin{array}{l}\text { Revista Debates } \\
\text { em Ensino de } \\
\text { Química. }\end{array}$ & Brasil & $\begin{array}{l}\text { Verbetes químicos. } \\
\text { Tabela periódica produzida } \\
\text { com recurso de baixa } \\
\text { tecnologia. } \\
\text { Objetos do cotidiano dos } \\
\text { alunos que contenham os } \\
\text { elementos químicos da } \\
\text { tabela. }\end{array}$ & Sim & Não \\
\hline $\begin{array}{l}\text { Nogueira, } \\
\text { Barroso e } \\
\text { Sampaio }\end{array}$ & $\begin{array}{l}\text { A importância das } \\
\text { libras: um olhar sobre } \\
\text { o ensino de química a } \\
\text { surdos. }\end{array}$ & 2018 & $\begin{array}{l}\text { Revista } \\
\text { Investigações } \\
\text { em Ensino de } \\
\text { Ciências. }\end{array}$ & Brasil & $\begin{array}{l}\text { Levantamento de termos } \\
\text { químicos em LIBRAS. }\end{array}$ & Sim & Não \\
\hline $\begin{array}{l}\text { Vertuan e } \\
\text { Santos. }\end{array}$ & $\begin{array}{l}\text { O ensino de Química } \\
\text { para alunos surdos: } \\
\text { uma Revisão } \\
\text { Sistemática; }\end{array}$ & 2019 & $\begin{array}{l}\text { Revista } \\
\text { Educação } \\
\text { Especial. }\end{array}$ & Brasil & Revisão Sistemática. & Não & Não \\
\hline Bastos & $\begin{array}{l}\text { Proposição de recursos } \\
\text { pedagógicos } \\
\text { acessíveis: } \\
\text { o ensino de química e } \\
\text { a tabela periódica. }\end{array}$ & 2016 & $\begin{array}{l}\text { Journal of } \\
\text { Research in } \\
\text { Special } \\
\text { Educational } \\
\text { Needs }\end{array}$ & $\begin{array}{l}\text { Estado } \\
\text { S } \\
\text { Unidos }\end{array}$ & $\begin{array}{l}\text { Verbetes químicos. } \\
\text { Tabela periódica produzida } \\
\text { com recurso de baixa } \\
\text { tecnologia. } \\
\text { Caixas de referência } \\
\text { contendo objetos do } \\
\text { cotidiano dos alunos que } \\
\text { contenham os elementos } \\
\text { químicos da tabela. }\end{array}$ & Sim & Não \\
\hline $\begin{array}{l}\text { Bastos, } \\
\text { Mastroiano e } \\
\text { Teixeira }\end{array}$ & $\begin{array}{l}\text { Glossário de vidrarias: } \\
\text { material de apoio ao } \\
\text { ensino de alunos com } \\
\text { deficiência visual. }\end{array}$ & 2016 & $\begin{array}{l}\text { 360 Encontro de } \\
\text { Debates sobre o } \\
\text { Ensino de } \\
\text { Química. }\end{array}$ & Brasil & Glossário em LIBRAS & Sim & Não \\
\hline
\end{tabular}

Fonte: Autores (2020). 
http://dx.doi.org/10.5902/1984686X48149

A seguir apresentamos reflexões sobre os artigos selecionados a partir das questões de pesquisa.

- QP1 - Existem recursos de acessibilidade para o ensino da tabela periódica para alunos surdos?

No que tange à primeira questão de pesquisa, foi possível observar que sim, a literatura nos mostra a existência de recursos de acessibilidade que podem ser trabalhados com alunos surdos para o ensino da tabela periódica.

- QP2 - Como ocorre o ensino referente aos conceitos da tabela periódica para alunos surdos?

A apresentação das reflexões para a QP2 está em ordem conforme o Quadro 5.

Sousa e Rocha et. al. (2015) apresentam uma bancada eletrônica de elementos químicos da tabela periódica com materiais reaproveitados (MDF, LED, base de pilhas, fios condutores elétricos, placa de fenolite cobreada, motor vibrador de celular, imã, resistor, chave liga-desliga e conectores). A proposta de utilização do recurso é voltada para alunos cegos e surdos. A bancada é organizada em blocos que correspondem aos elementos químicos identificados com símbolo em Braille e datilologia. Durante o manuseio, os alunos encaixam um bloco de pergunta com o nome do elemento químico que se deseja conhecer o símbolo na bancada. O próximo passo é colocar as letras na parte inferior da placa. Quando a combinação está correta, uma luz de LED é acesa. O brilho do LED é ajustável ao aluno com baixa visão e há um sistema de vibração para alunos cegos. O recurso possui um aporte visual importante para os alunos surdos. Entretanto, os autores não mencionam estratégias para mediação de outros conceitos referentes à tabela além do símbolo químico dos elementos. Neste ponto, fazemos uma reflexão sobre essa abordagem, visto que ela se baseia na memória. A tabela periódica não precisa ser decorada, pois esse instrumento pode ser consultado pelos alunos. Entender sua organização e aprender a identificar as informações organizadas nela seria mais enriquecedor. Os autores não mencionam proposição de sinais para os elementos.

Souza e Junior et. al. (2015) propõem trabalhar com recurso lúdico utilizando um jogo de cartas, onde os alunos devem consultar uma tabela periódica identificando os elementos químicos que são representados por imagens relacionadas ao dia-a-dia, de forma a facilitar o entendimento, além de ampliar a interação social entre os alunos ouvintes e alunos surdos. O jogo intenciona mediar conceitos como as características e propriedades da tabela (grupos e períodos) e ensinar como localizar os símbolos dos elementos químicos 
http://dx.doi.org/10.5902/1984686X48149

na tabela ao mesmo tempo que discute a aplicação desses elementos no cotidiano. $O$ recurso proposto pelos autores possui um enfoque no aporte visual e utiliza a contextualização para aproximar o conhecimento científico da realidade dos alunos, entretanto não menciona o uso da língua de sinais ou criação de sinais para os elementos.

Carvalho e César et. al. (2016) utilizam recursos tecnológicos para facilitar o acesso à informação: apresentações no Prezi; o software Periodic Table, publicado por Paul Alan Freshney, e a tabela periódica interativa desenvolvida por César, Reis e Aliane (2015). Os autores desenvolveram algumas atividades com objetivo de mediar os conceitos referentes a eletronegatividade dos elementos químicos e posteriormente ligações químicas iônica e covalente. Dentre as atividades realizadas, destacamos uma em que cada aluno deveria representar um elemento químico assumindo seu comportamento. Para diferenciá-los, foram utilizados coletes de tecido TNT com cores características; para representar os elétrons da camada de valência, foram utilizadas bolas de poliestireno (isopor). Essa atividade objetivou trabalhar os conceitos de elétrons na camada de valência e eletronegatividade.

A avaliação ocorreu por meio de perguntas aos alunos, que estavam dispostos em círculo para que pudessem se observar. Elas buscavam saber qual elemento poderia interagir com outro e que tipo de ligação seria estabelecida. Para respondê-las, os alunos deveriam saber as propriedades de cada elemento. As estratégias e recursos utilizados pelos autores também possuem aporte visual. Vale destacar que a atividade lúdica realizada possibilitou a interação entre os alunos, potencializando as trocas de conhecimento e envolvimento. Sobre a proposição de novos sinais, os autores relatam que, durante as aulas, sinais eram criados e recriados a partir da negociação entre alunos surdos, interprete e professor, após a apresentação de novos conceitos. O trabalho não menciona criação de sinais para elementos químicos. Mesmo assim, os pesquisadores mostram-se preocupados em tentar suprir a carência de sinais para termos químicos.

Bastos, Dantas e Teixeira (2017) e Bastos (2016) utilizam recursos de baixa tecnologia, construídos a partir das premissas do desenho universal da aprendizagem, da neurociência aplicada à educação e da temática da educação especial, para confeccionar uma tabela periódica acessível construída com materiais de baixa tecnologia. A tabela é dividida em três grupos (metais, ametais e gases nobres), cada um deles com uma cor (pista visual) e uma marca tátil (pista tátil). As cores foram escolhidas a partir das relações atribuídas pelos alunos entre os conhecimentos científicos, provenientes da química, e os 
http://dx.doi.org/10.5902/1984686X48149

conceitos naturais, provenientes de suas vivências. Por exemplo, a cor azul, atribuída aos gases nobres, partiu da sugestão dos surdos que a relacionavam ao botijão de gás de cozinha de mesma cor. No topo da coluna dos gases nobres dispõe-se um fogão de brinquedo com botijão de gás para ajudar na aproximação do termo gás. Os metais receberam cor cinza, que remete à cor característica dos metais do cotidiano, e os ametais não receberam cor, apenas uma borda preta para delimitar o elemento na tabela, criando uma dicotomia de que metal é representado com cor cinza e não metal é representado sem cor. Como marcas táteis, os metais foram representados com clipes metálicos, que é um objeto característico do grupo dos metais (o próprio metal), e os ametais não tinham legenda tátil, criando a mesma dicotomia usada nas cores. Os gases nobres estavam representados por lantejoulas azuis, da mesma cor do botijão. As lantejoulas foram escolhidas pelos próprios alunos cegos, pois já estavam habituados com esse tipo de material. Os símbolos de cada elemento foram dispostos em Braille e tinta. A tabela dispunha de bolsos transparentes para acomodar amostras dos elementos e, à parte, de caixas de referências com amostras de materiais que contém os elementos químicos em sua composição.

Os autores construíram também pequenos textos chamados de "verbetes", escritos a partir de uma linguagem clara, com correspondência na LIBRAS devido à carência de sinais para representar todos os elementos químicos, como já relatado anteriormente. Como apoio ao texto escrito, recorreu-se à utilização de Comunicação Alternativa, através de imagens e símbolos pictográficos (desenhos representativos da realidade a ser informada), o que permite o acesso ao conteúdo abordado por estes verbetes por alunos sem a funcionalidade dos processos de leitura. Esse trabalho não aborda a proposição de sinais, entretanto, ressalta-se o cuidado com a proposição dos verbetes, pois, assim como a tabela, eles possuem forte aporte visual e também trabalham a segunda língua do surdo (Língua Portuguesa) de forma adaptada, tornando-a de fácil compreensão e dando autonomia para que o surdo possa estudar sozinho quando necessário.

Bastos, Mastroiano e Teixeira (2016) apresentam um Glossário de Vidrarias de características táteis e visuais. Para além disso, os autores constroem verbetes sobre as vidrarias, cujo teor abarca a definição da vidraria, para quais situações ela é indicada e exemplos de uso. Os verbetes são apresentados em um DVD, tanto na Língua Portuguesa quanto na LIBRAS. Assim com o trabalho anterior, ressalta-se a relevância dos verbetes, principalmente sua aproximação ao cotidiano do aluno por meio de exemplos. 
http://dx.doi.org/10.5902/1984686X48149

É interessante destacar que os recursos apresentados pelas publicações são predominantemente visuais, conforme recomendam Gaudiot e Thoma $(2010,2014)$, pois o surdo é um indivíduo visual e necessita de relações da linguagem visual com as quais tenham oportunidade de interagir, a fim de desenvolver significado, proporcionando a aquisição de conhecimento.

- QP3 - Existem sinais que representem os elementos químicos em língua de sinais para alunos surdos?

A pesquisa identificou 8 elementos químicos (ouro, ferro, alumínio, hidrogênio, prata, oxigênio, fósforo, carbono). Nogueira, Barroso e Sampaio (2018) apresentam um levantamento de termos químicos em LIBRAS juntamente com símbolos para quatro elementos. Entretanto, seu artigo não disponibiliza os sinais na íntegra e, desse modo, não foi possível avaliar se correspondem a sinais-termos.

\section{Considerações finais}

A revisão mostra que há, na literatura, a proposição de recursos acessíveis para a tabela periódica voltados ao público surdo, mas a quantidade de publicações encontradas aponta que a discussão dessa temática ainda é recente. Utilizar o descritor "surdo" pode ter limitado os resultados da busca, excluindo trabalhos que propunham novos sinais para LIBRAS e, portanto, o termo "língua de sinais" talvez fosse mais adequado para este trabalho.

Apesar disso, os trabalhos encontrados revelam como foco no uso de recursos visuais para mediar os conceitos. Acreditamos que isso se deve à carência de termos químicos em LIBRAS, principalmente para os elementos da tabela periódica. Precisa haver produção de trabalhos realizados em conjunto com a comunidade surda para propor termos químicos em LIBRAS, não apenas para a tabela periódica, mas para todos os termos científicos utilizados no processo de ensino e aprendizagem.

Atribuir significados aos termos científicos impulsiona o estudante surdo à autonomia, permitindo que leia e compreenda textos científicos. Além disso, é direito do aluno surdo ser educado em sua primeira língua, a língua de sinais.

Assim, espera-se que este estudo possa chamar a atenção de professores e pesquisadores da área de educação para a importância de estudos voltados a este público. 
http://dx.doi.org/10.5902/1984686X48149

\section{Referências}

ALMEIDA, Maria Vani Magalhães; ALVES, José Moysés; JARDIM, Jecy Jane dos Santos; SALES, Elielson Ribeiro de. et al. 0 ambiente logo como elemento facilitador na releitura de significados em uma atividade de ciências com alunos surdos. In: Encontro Latino-Americano de Pós-Graduação, VII. São José dos Campos - SP. Anais... São José dos Campos-SP: UNIVAP, 2007.

ARAÚJO, Rafael; NUNES, Israel P.; REZENDE, Henrique de P. Concepção de um Jogo Digital Educativo usando Design Participativo para Ensino Contextualizado da Tabela Periódica. In: Workshops do Congresso Brasileiro de Informática na Educação. 2019. p. 524. Encontro Latino-Americano de Pós-Graduação. Anais... São José dos Campos-SP: UNIVAP, 2007.

BARRAL, Julia; DA SILVA, Wagner Seixas; RUMJANEK, Vivian M. O surdo e a ciência: aumentando a acessibilidade do jovem surdo ao conhecimento científico através do desenvolvimento de sinais técnicos/científicos em Língua Brasileira de Sinais. In: II Congresso Nacional de Ensino de Ciências e Formação de Professores-CECIFOP. 2017, Catalão. Congresso Nacional de Ciências e Formação de Professores-CECIFOP2017, Goiás - GO, 2017. v1. P.1130-1139.

BARRETO, Gislane Silverio Neto et al. História da Ciência nos livros didáticos de Química: Tabela Periódica como objeto de investigação. XVII Encontro Nacional de Ensino de Química, Florianópolis - SC, v. 18, 2016.

BASTOS, Amélia Rota Borges de. Proposição De Recursos Pedagógicos Acessíveis: 0 Ensino De Química e a Tabela Periódica. Journal of Research in Special Educational Needs, Hoboken, New Jersey, v. 16, p. 923-927, 2016.

BASTOS, Amélia Rota Borges de; DANTAS, Lucas Maia; TEIXEIRA, Raquel Lopes. Tabela Periódica Acessível: da proposição do recurso à implementação no ensino de alunos com deficiência visual. Revista Debates em Ensino de Química, Rio Grande RS, v. 3, n. 2 ESP, p. 34-49, 2017.

BASTOS, Amélia Rota Borges de; MASTROIANO, Yuri Freitas; TEIXEIRA, Raquel Lopes. Glossário de vidrarias: material de apoio ao ensino de alunos com deficiência. In: Encontro de Debates no Ensino de Química, 37 (37 EDEQ), Rio Grande. Atas. Rio Grande do Sul, 2016.

BRASIL, Câmara dos Deputados. Lei no 13.146, de 6 de julho de 2015. Institui a Lei Brasileira de Inclusão da Pessoa com Deficiência (Estatuto da Pessoa com Deficiência). Diário Oficial da União, 2015.

BRASIL, BRASÍLIA. Decreto № 5626 de 22 de dezembro de 2005. Regulamenta a lei no10, v. 436, 2005.

BRASIL. Constituição (1988). Constituição da República Federativa do Brasil. Brasília, DF, 1988. 
http://dx.doi.org/10.5902/1984686X48149

BRASIL, Lei 13.409 de 28 de dezembro de 2016. Diário Oficial da União, 2016.

BRASIL, Lei de Diretrizes. Lei no 10.436, de 24 de abril de 2002. Dispõe sobre a Língua Brasileira de Sinais-Libras e dá outras providências. Diário Oficial da União, 2002.

BRASIL, Lei. 9.394, de 20 de dezembro de 1996. Estabelece as Diretrizes e Bases da Educação Nacional. Diário Oficial da União, 1996.

CAPORALI, Sueli Aparecida; DIZEU, Liliane Correia Toscano de Brito. A língua de sinais constituindo o surdo como sujeito. Educação \& Sociedade, Campinas - SP, v. 26, n. 91, p. 583-597, 2005.

CARVALHO, Vinicius da Silva; et. al. A elaboração de material didático sobre o conteúdo de ligações químicas, iônica e covalente, voltado para o ensino do aluno surdo: uma proposta de sinais. In: Encontro Nacional de Ensino de Química, XVIII, Florianópolis -SC, 2016.

CÉSAR, Elói T.; REIS, Rita de C.; ALIANE, Cláudia S. de M. Tabela periódica interativa. Revista Química Nova na Escola, São Paulo - SP, v. 37, n. 3, p. 180-186, 2015.

CHARALLO, Thalita; FREITAS, Kátya; ZARA, Reginaldo. Mapa conceitual semiestruturado no ensino de conceitos químicos para alunos surdos. Encontro Nacional de Pesquisa em Educação em Ciências, Florianópolis - SC, v. 11, p. 1-9, 2017.

CHASSOT, Attico. Alfabetização científica: uma possibilidade para a inclusão social. Revista Brasileira de Educação, São Leopoldo, n. 22, p. 89-100, 2003.

CRUZ, Osilene; PRADO, Rosana. História da educação de surdos e as atuais perspectivas para o ensino de habilidades de leitura e escrita. Revista Inter Ação, v. 43, n. 3, p. 801-818, 2018.

DA ROCHA, Guilherme Sales; DE SOUZA LEAL, Wesley; MESSEDER, Jorge Cardoso. O uso da fotografia no estudo da tabela periódica/Use of photography in the periodic table study. Revista Dynamis, v. 25, n. 2, p. 205-223, 2019.

DA SILVA, Egle Katarinne Souza; LIMA, João Paulo Ferreira; FERREIRA, Maricélia Lucena. "Descobrindo os elementos químicos": jogo lúdico proporcionando uma aprendizagem significativa sobre a tabela periódica. Revista de Pesquisa Interdisciplinar, Cajazeiras - Paraíba, v. 1, n. Esp, 2016.

DE SÁ, Osilene Maria; DA CRUZ, Silva; PINHEIRO, Viviane Da Silva. Visualidade, Língua de Sinais e Conhecimento Prévio. Revista Communitas, v. 4, n. 7, p. 312-326, 2020.

DOS SANTOS, Adriana Vieira; ARAÚJO, Felipe Barbosa. Utilização de jogo didático para o ensino de tabela periódica. Revista Eletrônica Ludus Scientiae, v. 1, n. 2, 2017.

FAULSTICH, Enilde. Glossário sistêmico de Léxico terminológico para pesquisadores surdos. Brasília: Centro Lexterm, 2012. 
http://dx.doi.org/10.5902/1984686X48149

FAULSTICH, Enilde. 2014. Sinal-Termo. Nota lexical. Centro Lexterm. Disponível em: http://www.centrolexterm.com.br/notas-lexicais. Acesso em: 30 dez. 2019.

FERREIRA, Celeste Rodrigues; ARROIO, Agnaldo. O uso de visualizações no Ensino de Química: a formação inicial do professor de Química. Revista Brasileira de Ensino de Química. V. 4, n. 2, p. 31-42, 2009.

FERREIRA, Flora Maria Barros. Tabela Periódica Interactiva On-line: Uma Experiência Com Alunos do $10^{\circ}$ ano e Reformulação do Recurso Digital. Dissertação de Mestrado em Educação Multimédia, Universidade do Porto, Porto - PT. 2005.

FLÔR, Cristhiane Cunha; História da Ciência na Educação Química: Síntese de elementos transurânicos e extensão da Tabela Periódica. XIV Encontro Nacional de Ensino de Química (XIV ENEQ), ENEQ, 2008.

FNDE - Fundo Nacional de Desenvolvimento da Educação. Química - Conteúdo do Portal do FNDE. Disponível em: http://www.fnde.gov.br/component/k2/item/4083qu\%C3\%ADmica. Acesso em: 07 jun.2020.

GAUDIOT, Denise Maria Simões Freire. Sala de aula para surdos: recomendações ergonômicas. 2010. Dissertação de Mestrado, Programa de Pós-graduação em Design, Universidade Federal de Pernambuco, Recife - PE, 2010.

GODOI, Thiago André de Faria; OLIVEIRA, Hueder Paulo Moisés de; CODOGNOTO, Lúcia. Tabela periódica-um super trunfo para alunos do ensino fundamental e médio. Química nova na escola, v. 32, n. 1, p. 22-25, 2010.

GOLDFELD, Marcia. Fundamentos em fonoaudiologia: linguagem. Guanabara Koogan, 2003.

HONORA, Márcia. Inclusão educacional de alunos com surdez: concepções e alfabetização. São Paulo, SP: Cortez, 2014.

IBGE - Instituto Brasileiro de Geografia e Estatística. Estatísticas de gênero: uma análise do censo demográfico de 2010. Rio de Janeiro: IBGE, 2010. Disponível em: https://www.ibge.gov.br/apps/snig/v1/?loc=0\&cat=-1,-2,-3,128\&ind=4643. Acesso em: 07 jan. 2020.

Instituto Nacional de Estudos e Pesquisas Educacionais Anísio Teixeira (INEP). Censo Escolar, 2018. Brasília: MEC. 2018. Disponível em: http://portal.inep.gov.br/informacaoda-publicacao/-/asset_publisher/6JYIsGMAMkW1/document/id/6386080. Acesso em: 14 jan. 2020.

KITCHENHAM, Barbara. Procedures for performing systematic reviews. Tech. Report TR/SE-0401 Keele, UK, Keele University, v. 33, p. 1-26, 2004. 
LACERDA, Cristina Broglia Feitosa de. A inclusão escolar de alunos surdos: o que dizem alunos, professores e intérpretes sobre esta experiência. Cad. CEDES, Campinas, v. 26, n. 69, p. 163-184, Aug. 2006. Disponível em:

http://www.scielo.br/scielo.php?script=sci_arttext\&pid=S0101-

$32622006000200004 \&$ Ing=en\&nrm=iso. Acesso em: 05 jun. 2020.

LACERDA, Cristina. Broglia Feitosa de; POLETTI, Juliana. Esteves. A escola inclusiva para surdos: a situação singular do intérprete de língua de sinais. In: Fávero, O; Ferreira, W.; Ireland, T. \& Barreiros, D. (Orgs.) Tornar a educação inclusiva. (pp. 159-176). Brasília: Unesco/ANPED, v. 1. 2009.

LEITE, Bruno Silva. O ano internacional da tabela periódica e o ensino de química: das cartas ao digital. In: Química Nova [online], São Paulo - SP, vol. 42, n.6, abr. 2019, p.702-710. Disponível em http://static.sites.sbq.org.br/quimicanova.sbq.org.br/pdf/ED20190092.pdf. Acesso em: 07 jan. 2020.

LEITE, Helena S. A.; PORTO, Paulo A. Análise da abordagem histórica para a tabela periódica em livros de química geral para o ensino superior usados no Brasil no século XX. Química Nova, São Paulo, v. 38, n. 4, p. 580-587, Maio. 2015.

LOPES, Reinaldo José; HÖLZLE, Luís Roberto Brudna. Um Mergulho na Tabela Periódica. 1. ed. São Paulo: C6 Bank, 2019. 84p.

LUCA, Anelise Grünfeld de. et al. Uma abordagem histórica da tabela periódica. In: SANTOS, Sandra Aparecida dos (Org.); RIBEIRO, Marcus Eduardo Maciel (Org.). Ensino de Ciências: reflexões e diálogos. Rio do Sul: Unidavi, 2015, p. 14.

LUZ, Eloisa Rodrigues da. O Ensino de Química para Surdos: uma análise a partir da triangulação de dados. Trabalho de Conclusão de Curso. Instituto Federal de Educação, Ciência e Tecnologia de Goiás, Anápolis - Goiás, 2016.

MARINHO, Margot Latt. O ensino de Biologia: o intérprete e a geração de sinais. 2007. 144 f. 2007. Dissertação (Mestrado em Linguística) - Departamento de Linguística, Português e Línguas Clássicas, Universidade de Brasília, Brasília.

MEIRELES, Rosana Maria do Prado Luz; DA COSTA, Valdelúcia Alves. Educação Bilíngue de alunos surdos: experiências inclusivas na Escola Municipal Paulo Freire, Niterói (RJ). Dissertação de Mestrado em Educação, Universidade Federal Fluminense, Niterói - RJ, 2010.

MOURA, Maria Cecília de. Surdez e linguagem. In: LACERDA, Cristina Broglia Feitosa de; SANTOS, Lara Ferreira dos. (Org.). Tenho um aluno surdo, e agora?: introdução à Libras e educação de surdos. São Carlos: EdUFSCar, 2014. p.13-26.

NOGUEIRA, Emanuela Pinheiro; DA SILVA BARROSO, Maria Cleide; DE GOES SAMPAIO, Caroline. A importância da libras: um olhar sobre o ensino de química a surdos. Investigações em Ensino de Ciências, Porto Alegre - RS, v. 23, n. 2, p. 49-64, 2018. 
OLIVEIRA, Walquíria Dutra de; BENITE, Anna Maria Canavarro. Aulas de ciências para surdos: estudos sobre a produção do discurso de intérpretes de LIBRAS e professores de ciências. Ciência \& Educação, Bauru - SP, v. 21, n. 2, p. 457-472, 2015.

PEREIRA, Maria. Cristina Cunha; CHOI, Daniel; VIEIRA, Maria Inês; GASPAR, Priscila; NAKASATO, Ricardo. LIBRAS: conhecimento além dos sinais. São Paulo: Pearson Prentice Hall, 2011.

PERLIN, Gladis; STROBEL, Karin. Fundamentos da Educação de Surdos. Universidade Federal de Santa Catarina. Licenciatura em Letras/Língua Brasileira de Sinais, Florianópolis, 2006.

PONTARA, Amanda Bobbio. Desenvolvimento de sinais em Libras para o ensino de Química orgânica: um estudo de caso de uma escola de Linhares/ES. Dissertação de Mestrado, Universidade Federal do Espírito Santo, Espírito Santo, 2017.

REILY, Lucia. Escola Inclusiva: linguagem e mediação. 4. ed. Campinas. Papirus editora, 2004.

REIS, Esilene dos Santos. O ensino de Química para alunos surdos: desafios e práticas dos professores e intérpretes no processo de ensino e aprendizagem de conceitos químicos traduzidos para Libras. Dissertação de Mestrado, Programa de Pósgraduação em Ensino de Ciências e Matemática, Universidade Federal do Ceará, Fortaleza - CE, 2015.

RIBEIRO, Rafael Abdala Mendonça; DA SILVA, Roberto Ribeiro. Estudo da tabela periódica enfocando experimentos, história da ciência e sistemas conceituais. Revista Metáfora Educacional, Feira de Santana - BA, n. 21, p. 174-204, 2016.

SALDANHA, Joana Correia. O Ensino de Química em Língua Brasileira de Sinais. Dissertação de Mestrado, Universidade do Grande Rio, Duque de Caxias - RJ, 2011.

SAMPAIO, Rosana Ferreira; MANCINI, Marisa Cotta. Estudos de Revisão Sistemática: um guia para síntese criteriosa da evidência científica. Revista brasileira de fisioterapia, São Carlos - SP, v. 11, n. 1, p. 83-89, 2007. Disponivel em:

http://www.scielo.br/pdf/rbfis/v11n1/12.pdf. Acesso em: 31 jan. 2020.

SANTOS, Patricia Tuxi dos. A terminologia na língua de sinais brasileira: proposta de organização e de registro de termos técnicos e administrativos do meio acadêmico em glossário bilíngue. Dissertação de Mestrado, Universidade de Brasília, Brasília - DF, 2017.

SANTOS, Rosilene Montavoldão et al. Ensino de Conceitos Científicos no Contexto da Surdez: Uma Leitura Segundo a Perspectiva Sócio-histórica. Revista Experiências em Ensino de Ciências, v. 13, n. 5, p. 204-222, 2018. Disponível em: https://if.ufmt.br/eenci/artigos/Artigo_ID535/v13_n5_a2018.pdf. Acesso em: 27 mai. 2020. 
http://dx.doi.org/10.5902/1984686X48149

SOUSA, Jaliade Chaves et. Al. Bancada eletrônica de elementos químicos da tabela periódica para alunos com surdez e cegueira. In: 55 Congresso Brasileiro de Química, Goiânia - GO. Anais do CBQ, 2015.

SOUZA, Etiene Sizo de. et. al. Tecnologia de educação especial para o ensino de química aos alunos surdos. In: $55^{\circ}$ Congresso Brasileiro de Química, Goiânia - GO. Anais do CBQ, 2015.

THOMA, Adriana da Silva et al. Relatório sobre a política linguística de educação bilíngue: língua brasileira de sinais e língua portuguesa. Brasília: Ministério da Educação, 2014.

VERTUAN, Greice De Souza; DOS SANTOS, Lara Ferreira. O ensino de química para alunos surdos: uma revisão sistemática. Revista Educação Especial, Santa Maria- RS, v. 32, p. 44-1-20, 2019.

WHO - World Health Organization. Deafness and hearing loss. Disponível em: https://www.who.int/en/news-room/fact-sheets/detail/deafness-and-hearing-loss. Acesso em: 24 jul. 2020.

ZIESMANN, Cleusa Inês. Práticas pedagógicas em sala de aula com surdos:

implicações nos processos de ensino e de aprendizagem. Dissertação de Mestrado (Educação nas Ciências) Universidade Regional do Noroeste do Estado do Rio Grande do Sul, ljuí, 2015.

ZUCOLOTTO, Marcele Pereira da Rosa; RUIZ, Luciana Rodrigues; PINHEIRO, Najara Ferrari. REFLEXÕES SOBRE LINGUAGEM, SOCIEDADE E SURDEZ. Revista Uniabeu, Belford Roxo - RJ, v. 12, n. 30, 2019.

\section{Notas}

${ }^{1}$ Compreendida como uma perda auditiva superior à 40 decibéis $(\mathrm{dB})$ no ouvido com melhor capacidade auditiva do adulto e superior à $30 \mathrm{~dB}$ no ouvido com melhor capacidade auditiva da criança, a perda auditiva incapacitante pode ser leve, moderada, severa ou profunda e pode afetar um ou ambos os ouvidos (OMS, 2018).

\section{Correspondência}

Lucas Maia Dantas - Universidade Federal do Rio Grande, Av. Itália, s/n - Km 8 Carreiros, Rio Grande - Rio Grande do Sul - Brasil.

CEP: $96201-900$

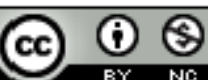

This work is licensed under a Creative Commons Attribution-NonCommercial 4.0 International (CC BY-NC 4.0) 